\title{
Hard Anodize of 6061-T0 Aluminium Alloy in Sulfuric Acid Bath at Near Zero Temperature and Its Mechanical Properties
}

\author{
Ndaru Adyono *, Wahyu Dwi Lestari \\ Universitas Pembangunan Nasional "Veteran" Surabaya, East Java, Indonesia
}

${ }^{*}$ Corresponding author:

E-mail:

ndaru.adyono.tm@upnjatim.ac.id

\begin{abstract}
Hard anodization was a method that can enhance aluminium alloy surface characteristics by growing an aluminum anodic oxide (AAO) film on it surface. This method was very applicable to obtain a thick and hard coating with a small amount of treatment time. This process was carried out at a high current density and low electrolyte temperature. Galvanostatic-potentiostatic mode at high current densities $(\mathrm{j}=4.2 \mathrm{~A} / \mathrm{dm} 2)$ and high target voltages $(\mathrm{Vt}$ $=30-60 \mathrm{~V}$ ) was used in this study. Two sulfuric acid electrolyte was compared, the first solution was sulfuric acid $11 \%$ vol., the second one was sulfuric acid $11 \%$ vol. plus oxalic acid $1 \%$ wt, both of them was conditioned at $>5^{\circ} \mathrm{C}$. The maximum AAO film thickness and hardness obtained was 110.01 $\mu \mathrm{m}$ and $400 \mathrm{HV}$. The increasment of target voltage was directly proportional to the increase in thickness and hardness of the AAO film.
\end{abstract}

Keywords: Hard anodizing, aluminium anodic oxide (AAO), hardness

\section{Introduction}

Aluminum alloys was one of the most commonly used metal materials in the industrial world. Aluminum was a low density material that had a high strength-to-weight ratio. However, aluminum alloys were suseptible to surface deterioation. These deficiencies become an obstacle to wider application (Dong, 2010).

Aluminium alloy surface characteristics can be enhanced electrochemically by hard anodization to grow a metal oxide on it surface. The layer formed is called the aluminum anodic oxide (AAO). Hard anodizing is performed to improve the surface performance of the material (hardness, abrasion and corrosion resistance). This method was very applicable in industry to obtain a thick $(50-70 \mu \mathrm{m})$ and hard (>250 HV) layer with a fast forming time $(0.83-1.67 \mu \mathrm{m} / \mathrm{min})$ (Lee $e t$ al., 2006). This AAO growth process was carried out at a high current density and electrolyte temperature which is conditioned close to zero degrees celsius. The use of electrolytes at very low temperatures was a key factor for producing a hard surface coating (Stepinowski et al., 2014).

According to Chu et al., (2005) and Schwirn et al., (2008) showed that power supply setup with the galvanostatic-potentiostatic mode at high current densities $\left(\mathrm{j}=2.5-100 \mathrm{~A} / \mathrm{dm}^{2}\right)$ and high target voltages $\left(\mathrm{V}_{\mathrm{t}}=27-80 \mathrm{~V}\right)$ at $1.8 \mathrm{M} \mathrm{H}_{2} \mathrm{SO}_{4}$ sulfuric acid electrolyte in low temperatures $\left(1^{\circ} \mathrm{C}\right)$ resulted an AAO film with a thickness in the range of $11.5-300 \mu \mathrm{m}$ using pure aluminum specimens (99.99\%). This approach was technically quite simple and cost-effective. Bensalah et al., (2010) compared the effect of anodization parameters on the AAO growing rate in AA1050 aluminum alloy specimens using a doehlert experimental design. The optimization study showed that the optimum anodization conditions ( $\mathrm{T}_{\text {electrolyte }} \leq 5.7^{\circ} \mathrm{C}, \mathrm{j}=3 \mathrm{~A} / \mathrm{dm}^{2}, \mathrm{C}_{\text {sulfur }}=1,4 \mathrm{M}$ ) resulted in a high AAO growing rate $(0.86 \mu \mathrm{m} / \mathrm{min})$ and a high film density $\left(3.12 \mathrm{~g} / \mathrm{cm}^{2}\right)$. Wu et al., (2019) found that two-step anodization could effectively widen the applications of AAO films, either as highprecision nanoporous templates or as ultrathin functional materials.

\section{How to cite:}

Adyono, N., \& Lestari, W. D. (2020). Hard anodize of 6061-T0 aluminium alloy in sulfuric acid bath at near zero

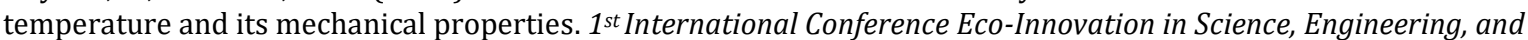
Technology. NST Proceedings. pages 96-101. doi: 10.11594/ nstp.2020.0514 
This study was a surface treatment that refers to the galvanostatic-potentiostatic mode by Chu et al., (2005) and Schwirn et al., (2008) as an electrical setup during the anodization process. Anodization parameters, especially current density and electrolyte temperature, adapted the optimization research from Bensalah et al., (2010). Research on hard anodizing Al6061 aluminum alloy using galvanostatic - potentiostatic electrical mode is still not much done. Aluminum alloy 6xxx series was one of the recommended alumnium alloys that were suitable for use as the parent metal to produce a tough and corrosion-resistant coating (ASM International Handbook, 1994).

This study used a sulfuric acid based electrolyte because sulfuric acid was an electrolyte that can be used in almost all alloys with a copper content limit not exceeding $5.0 \%$ and silicon not exceeding 7.0\% (ASM International Handbook V, 1994). In addition, this research also tries to optimize the mechanical properties of the coating by adding variations of oxalic acid $\mathrm{H}_{2} \mathrm{C}_{2} \mathrm{O}_{4}$ into the electrolyte solution (Febriyanti, 2011) .

\section{Research Method}

The specimen used in this study was a cylindrical aluminum alloy Al061-T0 (no heat-treatment) with a length of $25 \mathrm{~mm}$ and a diameter of $10 \mathrm{~mm}$. The AAO layer was grown only on the upper surface of the cylinder. Markers and non-sticky tape were used to chemically and electrically insulate the side and bottom surfaces of the cylinder. The upper surface of the specimen is smoothed with sandpaper (100-2000 grit size). Then chemically etched with $5 \% \mathrm{NaOH}$ solution at room temperature for two minutes and rinsed with distilled water.

The heat exchanger and agitation systems are combined into one in this research. Circulation in the heat exchange process is also used to maintain the solubility of ions $\left(\mathrm{Al}^{3+}, \mathrm{O}^{2-}\right)$ so that the electrolyte solution remains homogeneous. The circulating temperature of the solution was kept low $<5{ }^{\circ} \mathrm{C}$ during the anodization process. Electrical system uses a two-step electricity, the condition of a constant current (galvanostatic) and constant voltage (potensiostatic).

The schematic diagram of the tool is shown in Fig. 1. The anodization process is an exothermic reaction which causes the surface of the coating to heat up and heat up the electrolyte solution. During the coating process, the electrolyte solution is circulated to the heat exchanger system. Heat is dissipated from the copper coil to the cooling medium. The cooled electrolyte then returns to the electrolyte bath.

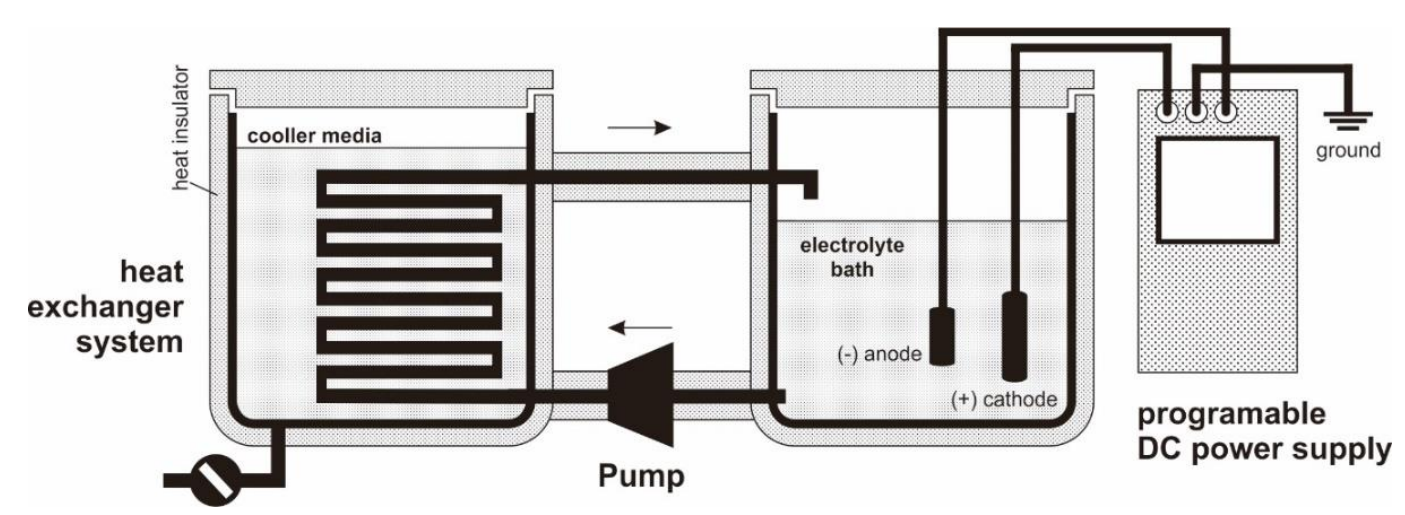

Figure 1 Schematic for hard anodizing surface treatment

The electrolyte solution is divided into two variations. The first variation (1) was sulfuric acid $11 \%$ vol. Dilution is carried out by slowly dissolving $224.5 \mathrm{~mL}$ of sulfuric acid $98 \%$ vol into $2 \mathrm{~L}$ of distilled water. The second variation (2) was sulfuric acid $11 \%$ vol plus oxalic acid $1 \%$ wt. Dilution is carried out by slowly dissolving $224.5 \mathrm{~mL}$ of sulfuric acid $98 \%$ vol into $2 \mathrm{~L}$ of distilled water plus 20 grams of oxalic acid powder. 
The anodization process begins with a galvanostatic condition at $4.2 \mathrm{~A} / \mathrm{dm}^{2}$ then switch to potentiostatic when it reaches the target voltage $\mathrm{V}_{\mathrm{t}}$ and then maintained until the current density decreased to $1.0 \mathrm{~A} / \mathrm{dm}^{2}$. The target voltage consists of three variations 30,40 and 60 Volts. Voltage, current and electrolyte temperature profiles were observed every minute using voltmeter, ammeter and thermometer.

The surface morphologies of the hard-anodized specimen at different target voltages were observed by Optical Microscopy (OM). The cross section of developed oxide layer was observed by Optical Microscopy to obtain the coating thickness. The micro-harnesses of the hard-anodized coating were observed with Micro Vickers method (Zalnezhad et al., 2013).

\section{Results and Discussion}

\section{Dissolution of anodic metal}

Aluminium alloy Al6061-T0 composition.

The composition limits for the specimen Al6061-T0 aluminium alloys in wt.\% are listed in Table 1 . The various alloying elements are present in the aluminium substrate as solid solutions, or second phases, such as zones, precipitates, or intermetallic compounds of various shapes, sizes and compositions. It plays role in AAO layer growth and microstructure during anodization.

Table 1 Alloy composition wt\% of Al 6061 T0 provided by The Aluminum Association (ASM Aerospace Specification Metal Inc, n.d.)

\begin{tabular}{cccccc}
\hline Component & Wt. \% & Component & Wt. \% & $\begin{array}{c}\text { Compo- } \\
\text { nent }\end{array}$ & Wt. \% \\
\hline $\mathrm{Al}$ & $95.8-98.6$ & $\mathrm{Mg}$ & $0.8-1.2$ & $\mathrm{Si}$ & $0.4-0.8$ \\
$\mathrm{Cr}$ & $0.04-0.35$ & $\mathrm{Mn}$ & $\mathrm{Max} 0.15$ & $\mathrm{Ti}$ & $\mathrm{Max} 0.15$ \\
$\mathrm{Cu}$ & $0.15-0.4$ & $\mathrm{Fe}$ & 0.7 & $\mathrm{Zn}$ & $\mathrm{Max} 0.25$ \\
\hline
\end{tabular}

\section{Ions transport mechanism}

Electrochemical anodization of Al6061-T0 aluminium alloys to form thick oxide layers has been carried out. Anodization was an electro-chemical process which can be described as a closed electrical circuit. Metal oxide formation reactions can occur through dissolution of anodic metals to form suitable cations followed by reactions between metal cations and ionic oxygen. The electric charge carriers that flowing through the AAO layer were $\mathrm{Al}^{3+}$ and $\mathrm{O}_{2}$ - The final reaction of aluminum oxidation:

$$
2 \mathrm{Al}^{3+}+3 \mathrm{H}_{2} \mathrm{O} \rightarrow \mathrm{Al}_{2} \mathrm{O}_{3}+6 \mathrm{H}^{+}+6 e^{-}
$$

\section{Anodization}

Electrical and temperature profile

The electrical profile of the target voltage 40V was shown in Fig. 2a. The use of $11 \%$ vol sulfuric acid electrolyte with the addition of $1 \%$ oxalic acid had a higher current density profile than without addition. Fig. $2 \mathrm{~b}$ shows that the use of $11 \%$ vol sulfuric acid electrolyte with the addition of $1 \%$ oxalic acid can reduce the electrolyte temperature profile during the anodization. Temperature reduction optimizes electrical processes. The temperature reduction optimizes the electrical process and increases the reaction formation of $\mathrm{Al}_{2} \mathrm{O}_{3}$ then speeds up the $\mathrm{AAO}$ layer growth process, resulting in a thicker layer. 


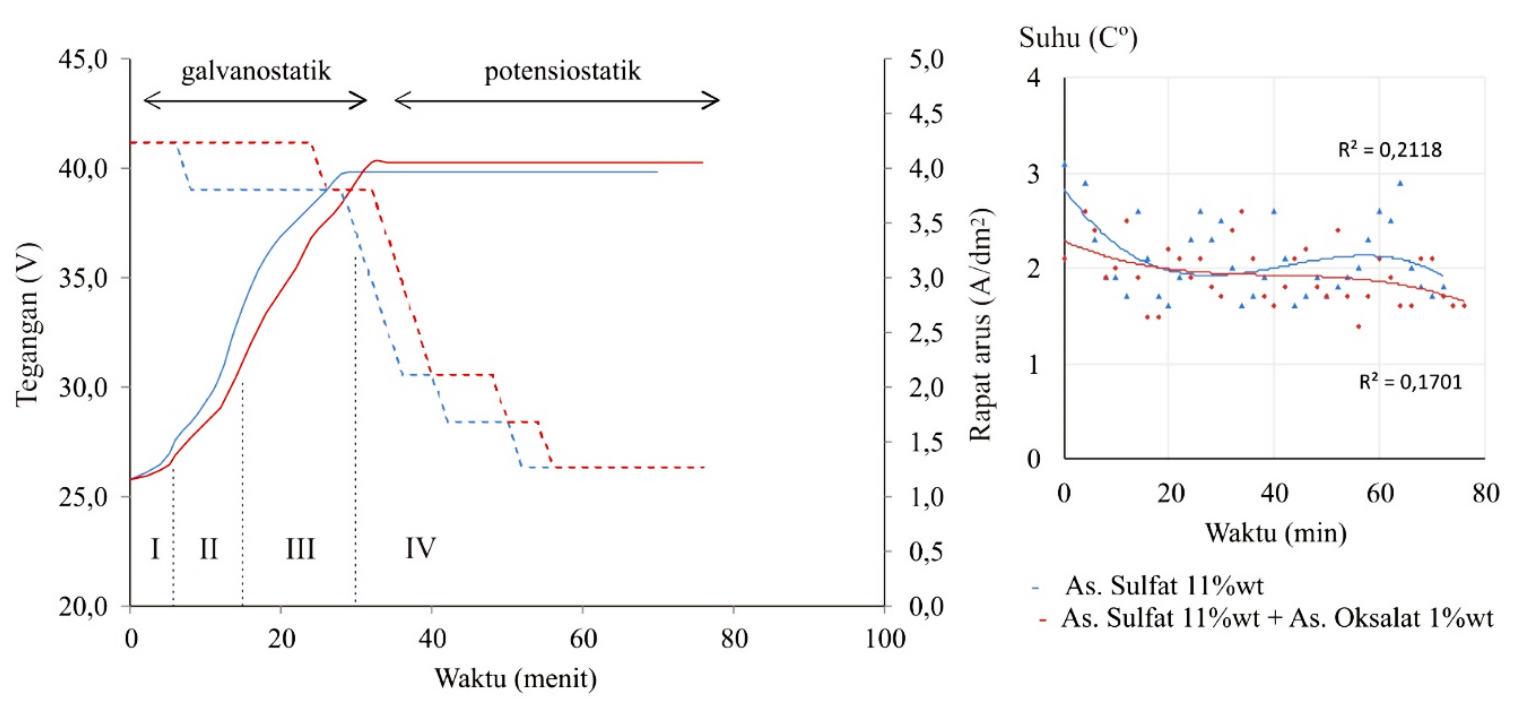

$\begin{array}{rlr}\text { Tegangan }: & - \text { As. Sulfat } & \text { As. Sulfat }+ \text { As. Oksalat } \\ \text { Arus }: & \ldots-\text { As. Sulfat } & -\cdots \text { As. Sulfat }+ \text { As. Oksalat }\end{array}$

Figure 2. Electrical profile (a) and temperature profile (b) during the hard anodizing process at the target voltage $\mathrm{Vt}=40 \mathrm{~V}$
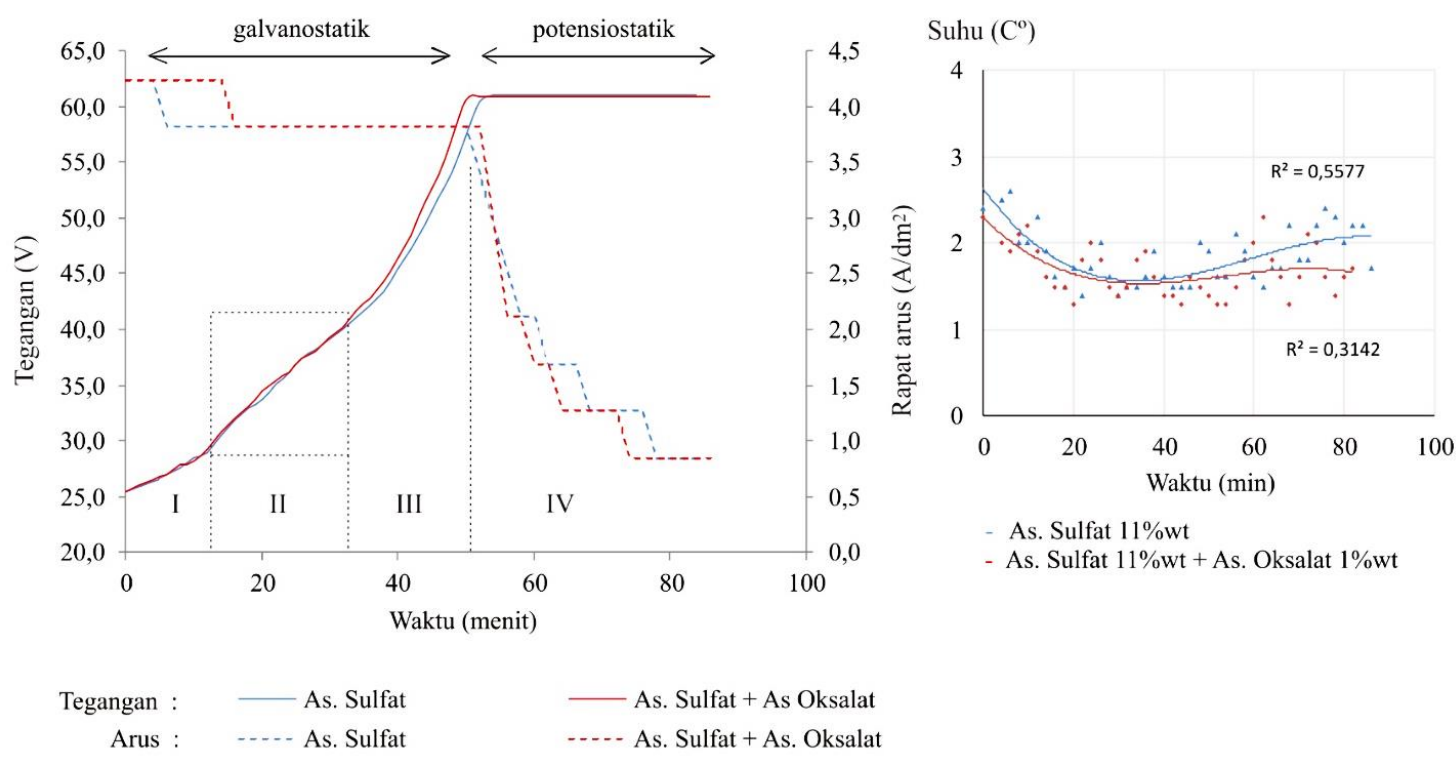

As. Sulfat $11 \% \mathrm{wt}$

- As. Sulfat $11 \% \mathrm{wt}+$ As. Oksalat $1 \%$ wt

Figure 3. Electrical profile (a) and temperature profile (b) during the hard anodizing process at the target voltage $\mathrm{Vt}=60 \mathrm{~V}$

There was a slight difference in the electrical profile in Fig. 3 (a) on the target voltage parameter $\mathrm{V}_{\mathrm{t}}=60 \mathrm{~V}$. The current density in the $11 \%$ vol sulfuric acid electrolyte with the addition of $1 \%$ wt oxalic acid (red stripe) at the 5 to 55 minute was higher than the current density in the $11 \%$ vol sulfuric acid electrolyte (blue stripe), However, from the 55 minute till the end of the anodization, the current density in the $11 \%$ vol sulfuric acid electrolyte with the addition of $1 \%$ wt oxalic acid (red stripe) was lower than the current density at anodization in the $11 \%$ vol sulfuric acid electrolyte (blue stripe line). 


\section{AAO layer growth}

The relationship between the target voltage and thickness in Fig. 4 shows that the variation of $1 \%$ wt addition of oxalic acid was good for use at target voltages below $50 \mathrm{~V}$. The use of target voltage above $50 \mathrm{~V}$ results in reduction $\Delta$ in layer thickness. The use of voltages above $50 \mathrm{~V}$ was more suitable for variations of the $11 \%$ vol sulfuric acid electrolyte without the addition of $1 \% \mathrm{wt}$ oxalic acid.

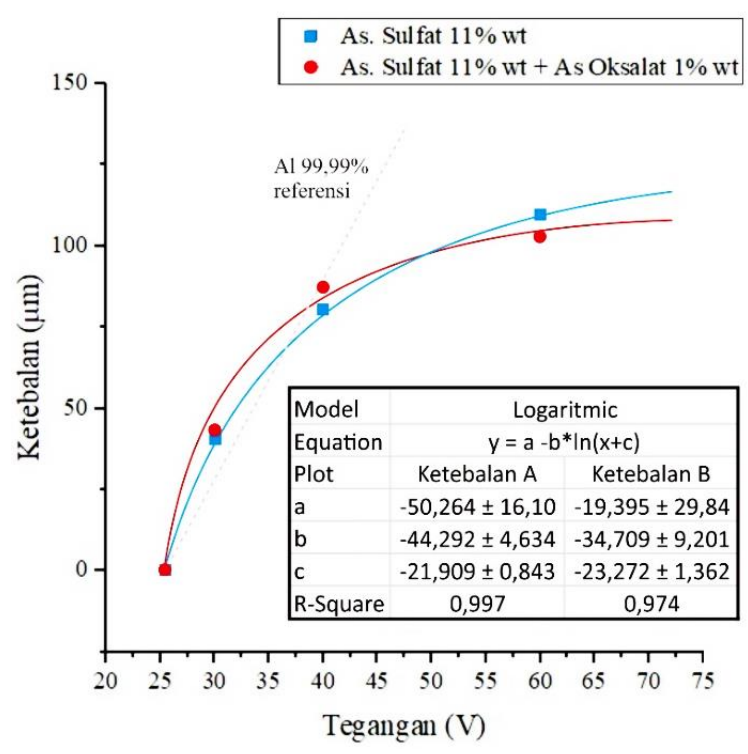

Figure 4 Plot $V_{t}$ target voltage vs thickness

The micro-hardness of AAO Layer

The AAO layer increases its hardness significantly as the target voltage increases. The relationship of target voltage with the thickness and hardness was shown in Fig. 5. The diagram with a solid color bar shows the hardness value, while the shaded colored bars show the thickness value. The blue color shows speciments in $11 \%$ vol $\mathrm{H}_{2} \mathrm{SO}_{4}$ sulfuric acid electrolyte, while the red color shows speciments in $11 \% \mathrm{vol}_{2} \mathrm{SO}_{4}$ sulfuric acid electrolyte with the addition of $1 \% \mathrm{wt}$ $\mathrm{H}_{2} \mathrm{C}_{2} \mathrm{O}_{4}$ oxalic acid.

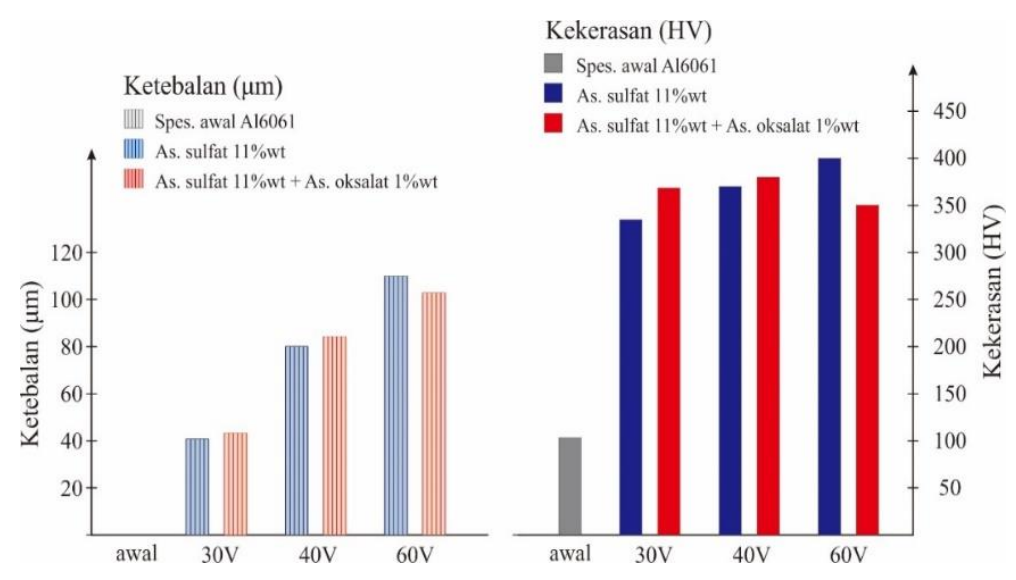

Figure 5. Chart of AAO Layer thickness and hardness in different electrolyte solutions and target voltages. 
The initial voltage (25V) in Fig. 5 was the initial electrical breakdown voltage. In the initial voltage condition, it is assumed that the AAO layer has not been formed and the hardness value same as the initial specimen hardness value $103.5 \mathrm{HV}$. The thickness and hardness of the layers were directly proportional to the increase in target volltage $V_{t}$.

\section{Conclusion}

The addition of $1 \%$ wt oxalic acid into the $11 \%$ vol sulfuric acid electrolyte can optimize the growth rate of AAO layer when using a target voltage bellow $50 \mathrm{~V}$. The maximum layer thickness in this study was $110.01 \mu \mathrm{m}$ which was produced using $11 \%$ vol sulfuric acid electrolyte with current density $4.2 \mathrm{~A} / \mathrm{dm}^{2}$, target voltage $60 \mathrm{~V}$ and electrolyte temperature bellow $5{ }^{\circ} \mathrm{C}$.

The target voltage variations $(30 \mathrm{~V}, 40 \mathrm{~V}$ and $60 \mathrm{~V})$ was directly proportional to the increase in thickness and hardness. Increasing the target voltage of $30 \mathrm{~V}, 40 \mathrm{~V}$ and $60 \mathrm{~V}$ at the variation of the sulfuric acid electrolyte of $11 \%$ vol produced AAO layers with a hardness of $334.8 \mathrm{HV} ; 370.0 \mathrm{HV}$ and $400.0 \mathrm{HV}$. While increasing the target voltage of $30 \mathrm{~V}, 40 \mathrm{~V}$ and $60 \mathrm{~V}$ in the electrolyte with the addition of $1 \%$ wt oxalic acid produces layers with a hardness of $368.5 \mathrm{HV} ; 380.0 \mathrm{HV}$ and 350.4 HV.

\section{Acknowledgment}

We would like to thanks to the Allah SWT and parents.

\section{References}

ASM Aerospace Specification Metal Inc, n.d. Aluminum 6061-T6; 6061-T651.

ASM International Handbook Committee. (1994). ASM Handbook Vol. 5 Surface Engineering. 9th ed. ASM International.

ASTM. (1997). ASTM B487-85 Standard Test Method for Measurement of Metal and Oxide Coating Thickness by Microscopical Examination of a Cross Section.

Bensalah, W., Feki, M., Wery, M., \& Ayedi, H. F. (2010). Thick and Dense Anodic Oxide Layers Formed on Aluminum in Sulphuric Acid Bath. Journal of Materials Science Technology, 26(2), 113-118.

Chu, S.Z., Wada, K., Inoue, S., Isogai, M., \& Yasumori, A. (2005). Fabrication of ideally ordered nanoporous alumina films and integrated alumina nanotubule arrays by high-field anodization. Advanced Materials, 17(17), 2115-2119.

Dong, H. (2010). Surface Engineering of light alloys. I ed. Woodhead Publishing Limited.

Febriyanti, E. (2011). Optimasi Proses Pelapisan Anodisasi Keras. Majalah Metalurgi, 5, pp.109-116.

Lee, W., Ji, R., Gosele, U. G. \& Nielsch, K., (2006). Fast fabrication of long-range ordered porous alumina membranes by hard anodization. nature materials, 5(9), 741-747.

Runge, J. M. (2017). The Metallurgy of Anodizing Aluminum. Chicago, USA: Springer.

Schwirn, K., Lee, W., Hillebrand, R., Steinhart, M., Nielsch, K., \& Gösele, U., (2008). Self-ordered anodic aluminum oxide formed by H2SO4 hard anodization. ACS nano, 2(2), 302-310.

Stepinowski, W.J., Nowak-st, A., Presz, A., Czujko, T., \& Varin, R.A. (2014). The effects of time and temperature on the arrangement of anodic aluminum oxide nanopores. Material characterization, 1,1-9.

Wu, J., Li, Y., Li, Z., Li, S., Shen, L., Hu, X., \& Ling, Z. (2019). Ultra-slow growth rate : Accurate control of the thickness of porous anodic aluminum oxide films. Electrochemistry Communications, 109(11), 6-10. https://doi.org/10.1016/j.elecom.2019.106602 